\title{
Severe rheumatic mitral stenosis with pericardial effusion causing left ventricular tamponade
}

\author{
S W Davies, A Youhana, M Copp
}

\begin{abstract}
A woman of 38 was admitted for urgent surgery of severe mitral stenosis causing pulmonary oedema. Echocardiography showed a pericardial effusion with apparent distortion and collapse of the left ventricle. Urgent drainage of the effusion before mitral valve surgery led to an improvement in cardiac output with no detectable change in right heart pressures.
\end{abstract}

Cardiac tamponade caused by pericardial effusion predominantly affects the right side of the heart, resulting in venous paradox (Kussmaul's sign) and visible compression and distortion of the right ventricle on cross sectional echocardiography ${ }^{1}$ However, in severe pulmonary hypertension tamponade may lead to preferential compression and distortion of the left heart. ${ }^{2}$ This effect is attributed to the high right heart pressures or hypertrophy, or both. We report a patient with severe mitral stenosis in whom a moderately sized pericardial effusion led to collapse of the left ventricle, which was visualised by echocardiography, and in whom drainage of the effusion led to an improvement in haemodynamic function.

\section{Case report}

A 38 year old woman from Bangladesh was admitted with sudden onset of severe dyspnoea and in a state of collapse. She was unable to give a history but later it became known that she had been breathless on exertion for the previous three years. On examination she had cold and sweaty hands and feet with a blood pressure of $70 / 40 \mathrm{mmHg}$, an irregular pulse rate ( 150 beats per minute), and a respiratory rate of 32 per minute. The chest $x$ ray showed pulmonary oedema and an enlarged cardiac silhouette with a configuration that suggested left atrial enlargement. She was urgently intubated and ventilated with intermittent positive pressure ventilation.

The electrocardiogram showed atrial fibrillation with a ventricular rate of approximately 160 beats per minute. Further clinical examination showed a left parasternal heave, very loud first heart sound, accentuated pulmonary second sound, and an early but quiet opening snap with a long and loud diastolic murmur at the apex. $M$ mode and cross sectional echocardiography confirmed the appearance of severe mitral stenosis with an enlarged left atrium and right heart. The patient remained hypotensive with cold extremities and a low urine output of 5 to $10 \mathrm{ml} /$ hour. Swan-Ganz catheterisation showed a mean right atrial pressure of $28 \mathrm{mmHg}$ and a mean pulmonary artery pressure of $78 \mathrm{mmHg}$; a satisfactory pulmonary wedge pressure tracing could not be obtained.

The cross sectional echocardiogram also showed a moderately sized pericardial effusion with apparent distortion and collapse of the left ventricle in some but not all cardiac cycles. While arrangements were made for urgent mitral valve replacement it was decided to drain the pericardial fluid in an attempt to improve the cardiac output. After $600 \mathrm{ml}$ of serous fluid was removed by subxiphoid pericardiotomy ${ }^{3}$ the systemic blood pressure rose to $80 / 50 \mathrm{mmHg}$, heart rate fell from 135 to 110 beats per minute in atrial fibrillation, cardiac output determined by thermodilution (Swan-Ganz catheter) improved from 1.8 to $2.6 \mathrm{l} / \mathrm{min}$, and right heart pressures were unchanged.

One hour later mitral valve replacement was performed via a median sternotomy. The native mitral valve was very thickened with rolled edges and fibrotic contraction of the papillary muscles and chordae tendineae: the valve orifice area was approximately $0.5 \mathrm{~cm}^{2}$. The mitral valve was replaced with a number 27 Björk-Shiley prosthetic valve. At the end of cardiopulmonary bypass the pulmonary artery systolic pressure was $120 \mathrm{mmHg}$ and the systemic arterial systolic pressure $100 \mathrm{mmHg}$. The patient required inotropic support and ventilation for 48 hours but she subsequently made an uncomplicated recovery.

\section{Discussion}

The haemodynamic features of cardiac tamponade are complex and may differ between patients. ${ }^{4}$ Animal experiments suggest that right sided cardiac compression contributes more to the haemodynamic derangement than does left heart compression. ${ }^{25}$ Echocardiographic studies in patients consistently show right atrial diastolic collapse whereas left atrial and right ventricular diastolic collapse are variable findings. ${ }^{6}$

Several reports suggest that the clinical and echocardiographic signs of cardiac tamponade may be atypical in patients with pulmonary hypertension and right ventricular hypertro-
Correspondence to: Dr S W Davies, Cardiac Department, The London Chest Hospital, Bonner
The London Chest S W Davies 
phy. Arterial pulsus paradoxus may be absent, and this has been attributed to increased impedance to the normal inspiratory increase in right ventricular filling. ${ }^{89}$ Echocardiographic studies show that right ventricular collapse may be absent if right ventricular hypertrophy is severe. ${ }^{21011}$ Preferential left atrial compression has been described in such a patient. ${ }^{12}$ Preferential compression of the left heart may also occur with loculated pericardial effusions or haematomas. ${ }^{13}$

We are not aware of any previous reports of compression of the left ventricle caused by a generalised pericardial effusion without compression of the other cardiac chambers. The improvement in cardiac output after drainage of the effusion showed the haemodynamic importance of the effusion in this patient. The haemodynamic effects of tamponade with mitral stenosis may differ from those in patients with tamponade and pulmonary hypertension owing to other causes, in whom left atrial diastolic collapse may be important-such collapse was not seen in our case, presumably because left atrial pressure was high.

We are grateful to Dr R Balcon and Mr P Magee for permission to report a patient under their care.
1 Armstrong WF, Schilt BF, Helper DJ, Dillon JC, Feigenbaum $\mathrm{H}$. Diastolic collapse of the right ventricle with cardiac tamponade: an echocardiographic study. Circulation 1982;65:1491-6.

2 Leimgruber PP, Klopfenstein HS, Wann LS, Brooks HL. The hemodynamic derangement associated with right
ventricular diastolic collapse in cardiac tamponade: an ventricular diastolic collapse in cardiac tamponade: an
experimental echocardiographic study. Circulation 1983;68:612-20.

3 Larrey DJ. New surgical procedure to open the pericardium and to determine the cause of fluid in its cavity. Clin Chirurg 1829;38:393.

4 Reddy PS, Curtiss EI, O'Toole JD, Shaver JA. Cardiac tamponade: hemodynamic observations in man. Circulation 1978;58:265-72.

5 Fowler NO, Gabel M, Buncher CR. Cardiac tamponade: a comparison of right versus left heart compression. J Am Coll Cardiol 1988;12:187-93.

6 Kronzon I, Cohen ML, Winer HE. Diastolic atrial compression: a sensitive echocardiographic sign of cardiac tamponade. J Am Coll Cardiol 1983;2:770-5.

7 Singh S, Wann LS, Klopfenstein HS, Hartz A, Brooks HL. Usefulness of right ventricular diastolic collapse in diagnosing cardiac tamponade and comparison to pulsus paradoxus. Am J Cardiol 1986;57:652-6.

8 Braunwald E. Heart disease. 3rd ed. Philadelphia: WB Saunders, 1988:1495.

9 Frey MJ, Berko B, Palevsky H, Hirshfeld JW Jr, Herrmann HC. Recognition of cardiac tamponade in the presence of severe pulmonary hypertension. Ann Intern Med 1989; severe pulm

10 Gaffney FA, Keller AM, Peshock RM, Lin J-C, Firth BG. Pathophysiologic mechanisms of cardiac tamponade and pulsus alternans shown by echocardiography. Am J Cardiol 1984;53:1662-6.

11 Singh S, Wann S, Schuchard GH, Klopfenstein HS, Leimgruber PP, Keelan MH Jr, et al. Right ventricular and right atrial collapse in patients with cardiac tamponade - a combined echocardiographic and haemodynamic study. Circulation 1984;70:966-71.

12 Brodyn NE, Rose MR, Prior FP, Haft JI. Left atrial compression in a patient with a large pericardial effusion and pulmonary hypertension. Am J Med 1990;8:64N-6N.

13 Kronzon I, Cohen ML, Winer HE. Cardiac tamponade by loculated pericardial hematoma: limitations of $M$-mode echocardiography. J Am Coll Cardiol 1983;1:913-5. 